\title{
Role of Krüppel-like factor 4 and heat shock protein 27 in cancer of the larynx
}

\author{
JIHAD KARAM ${ }^{1}$, MARIE CLAUDE FADOUS-KHALIFÉ ${ }^{1,2}$, RITA TANNOUS ${ }^{1}$, SALLY FAKHREDDINE ${ }^{1}$, \\ MARCEL MASSOUD $^{2}$, JOSEPH HADCHITY ${ }^{1,3}$, GEORGES AFTIMOS ${ }^{4}$ and ELIE HADCHITY ${ }^{1}$ \\ ${ }^{1}$ Anti-Tumor Therapeutic Targeting Laboratory, Faculty of Sciences, Lebanese University, Hadat 1003; \\ ${ }^{2}$ Notre Dame de Secours University Hospital, Jbeil 1401; ${ }^{3}$ Department of Surgery, St. Therese Hospital, \\ Hadat 1003; ${ }^{4}$ National Institute of Pathology, Baabda 1003, Lebanon
}

Received February 22, 2017; Accepted June 7, 2017

DOI: $10.3892 / \mathrm{mco} .2017 .1412$

\begin{abstract}
Late detection and lack of standard treatment strategies in larynx cancer patients result in high levels of mortality and poor prognosis. Prognostic stratification of larynx cancer patients based on molecular prognostic tumor biomarkers may lead to more efficient clinical management. Krüppel-like factor 4 (KLF4) and Heat Shock Protein 27 (HSP27) have an important role in tumorigenesis and are considered promising candidate biomarkers for various types of cancer. However, their role in larynx carcinoma remains to be elucidated. The present study aimed to determine KLF4 and HSP27 expression profiles in laryngeal tumors. The protein and $\mathrm{mRNA}$ expression levels of KLF4 and HSP27 were evaluated by immunohistochemical and reverse transcription-polymerase chain reaction analyses in 44 larynx carcinoma samples and 21 normal tissue samples, and then correlated with clinical characteristics. A differential expression of KLF4 and HSP27 was observed between normal and tumor tissues. The protein and mRNA expression levels of KLF4 were significantly decreased in larynx squamous cell carcinoma (LSCC) compared with normal tissue, whereas HSP27 was significantly overexpressed in tumor tissues compared with normal tissues, at the protein and mRNA levels. KLF4 expression decreased gradually with tumor progression whereas HSP27 expression increased. A significant difference was observed between stages I and IV. KLF4 and HSP27 exhibit opposite functions and roles in the carcinogenic process of LSCC. Their role in laryngeal cancer initiation and progression emphasizes their use as potential future targets for prognosis and treatment. KLF4 and HSP27 expression levels may act as potential biomarkers in patients with cancer of the larynx.
\end{abstract}

Correspondence to: Dr Elie Hadchity, Anti-Tumor Therapeutic Targeting Laboratory, Faculty of Sciences, Lebanese University, Hadat Educational Campus, Hadat 1003, Lebanon

E-mail: eliehadchity@hotmail.com

Key words: larynx cancer, KLF4, HSP27, immunohistochemistry, RT-PCR, prognostic markers

\section{Introduction}

Laryngeal squamous cell carcinoma (LSCC) is the second most common malignant neoplasm of head and neck squamous cell carcinoma. It is an aggressive malignancy associated with high rates of metastasis, recurrence and a low 5-year survival rate. It has a high incidence and primarily involves therapeutic failure especially for the advanced cases $(1,2)$. Therefore, identifying novel potential prognostic markers may lead to an improved clinical management of patients with laryngeal cancer.

Krüppel-like factors (KLFs) are a family of DNA binding transcriptional regulators expressed in a wide variety of human tissues. These factors have diverse and essential functions in multiple cell processes, including proliferation, inflammation, differentiation, migration, pluripotency, maintenance of homeostasis, and apoptosis $(3,4)$. KLF4 is a bifunctional transcription factor able to either activate or repress transcription using different mechanisms, depending on the target gene. Thus, depending on the cell type or cell context or cancer stage, KLF4 may act either as a tumor suppressor gene or as an oncogene. KLF4 is involved in cell cycle, where it can induce cycle arrest in some molecular contexts, while favoring proliferation in others (5). In colorectal and gastric cancers, KLF4 expression decreases at early stages due to different mechanisms including loss of heterozygosity, hypermethylation of the promoter and point mutations in the KLF4 gene, and may be lost with tumor growth and progression (6-8). Moreover, it was found that KLF4 is downregulated at the mRNA and protein levels in several non-small cell lung carcinoma cell lines, partially due to promoter hypermethylation. The restoration of KLF4 expression inhibits the clone formation and induces a delay in in vivo tumor growth (9).

KLF4 is overexpressed in $70 \%$ of primary mammary cancers at the stage of ductal carcinoma, where it plays an oncogenic role. In addition, nuclear localization of KLF4 in ductal carcinoma predicts an unfavorable outcome $(10,11)$. Previous findings showed the beneficial side of knocking down $\mathrm{KLF} 4$, as p53-dependent cell death is restored (12). In head and neck squamous cell carcinoma (HNSCC) tissues, persistent KLF4 expression predicts poor prognosis and confers aggressiveness (13). Recent studies showed that KLF4 is upregulated 
in small cell lung carcinoma tissues and has a potential tumor-promoting role in this type of lung malignancy (14).

Heat shock proteins (HSPs) are highly conserved molecular chaperones with principal roles in protein homeostasis, transport processes and signal transduction. Recently, heat shock proteins, found to be overexpressed in a wide range of malignancies, have been considered as promising candidate biomarkers for some cancers (15-17). Heat shock protein 27 (HSP27) is a molecular chaperone highly expressed in aggressive cancers, where it is involved in numerous pro-tumorigenic signaling pathways $(18,19)$. Overexpression of HSP27 was observed across different types of cancer including breast, ovarian, prostate, bladder, gastric, and oral squamous cell carcinoma and many others $(18,20)$. Its overexpression contributes to cancer progression via different mechanisms, and its anti-apoptotic and pro-survival activities play crucial roles in tumorigenesis. HSP27 increases proliferation by facilitating cell cycle progression and enhances migration and invasion via several mechanisms $(21,22)$. Additionally, high levels of HSP27 have been associated with poor prognosis and chemo- and radioresistance in various cancers including prostate, breast, head and neck and lung cancer $(21,23-27)$. HSP27 is now considered an attractive therapeutic target for cancer treatment. In vitro and in vivo studies have shown that the downregulation of HSP27 protein expression using antisense oligonucleotides or siRNA contributes in the reduction of tumor progression, induction of apoptosis and tumor sensitization to treatment (27-29). The strategy of HSP27 gene inhibition, using Apatorsen (OGX-427) a 2'-methoxyethyl-modified antisense oligonucleotide, has shown a promising therapeutic effect in clinical application. A phase I dose-escalation study showed a good tolerance of Apatorsen, associated with a decrease in tumor markers and in circulating tumor cells and a stable measurable disease in patients with castration-resistant prostate, breast, ovary, lung, and bladder cancer (30).

Only a few studies have investigated the potential role and the profile of mRNA and protein expression of HSP27 in laryngeal squamous cell carcinoma tissues $(31,32)$. Nevertheless, no studies have assessed the role and the expression of KLF4 in laryngeal cancer tissues. In this study, we examined the KLF4 and HSP27 mRNA and protein levels, by RT-PCR and immunohistochemical analyses, respectively, in laryngeal tumors $(n=44)$ and normal tissues $(n=21)$. We also evaluated the combinational clinical significance of KLF4 and HSP27 expression for the diagnosis or prognosis and treatment decision-making in laryngeal cancers.

\section{Materials and methods}

Sample collection. Forty-four formalin-fixed paraffinembedded larynx carcinoma samples and 21 normal tissue samples were collected from the Department of Pathological Anatomy of the Notre Dame de Secours University Hospital (Byblos, Lebanon) and the National Institute of Pathology (Baabda, Lebanon). Following surgical removal, all the tissue samples were fixed in formalin and embedded in paraffin prior to sectioning for histological, immunohistochemical and gene expression analyses. The cancer tissue samples were graded independently by a pathologist and histologically classified. Epidemiological and clinical data were collected from patient
Table I. Patient characteristics.

\begin{tabular}{lc}
\hline Characteristics & No. $(\%)$ \\
\hline Total Subjects & 65 \\
Normal tissues & $21(32.3)$ \\
Tumor tissues & $44(67.7)$ \\
Sex & \\
Male & 83.1 \\
Female & 16.9 \\
Age median (range), years & $65(47-88)$ \\
Stage & \\
I & $9(20.5)$ \\
II & $11(25)$ \\
III & $6(13.6)$ \\
IV & $18(40.9)$ \\
\hline
\end{tabular}

Table II. Results of KLF4 immunostaining in normal and tumor tissues (cases per intensity of expression).

\begin{tabular}{lccc}
\hline $\begin{array}{l}\text { Protein } \\
\text { expression }\end{array}$ & $\begin{array}{c}\text { Normal } \\
\text { tissue }(\%)\end{array}$ & $\begin{array}{c}\text { Tumor } \\
\text { tissue }(\%)\end{array}$ & $\begin{array}{c}\text { P-value } \\
\text { (normal vs. tumor) }\end{array}$ \\
\hline 0 & $3(14.3)$ & $27(61.4)$ & $<0.001$ \\
$1+$ & $14(66.7)$ & $7(15.9)$ & $<0.001$ \\
$2+$ & $4(19)$ & $7(15.9)$ & $>0.05$ \\
$3+$ & $0(0)$ & $3(6.8)$ & $>0.05$ \\
\hline
\end{tabular}

records and registries (Table I). This study was approved by the Institutional Review Board of the Notre Dame de Secours University Hospital.

Immunohistochemistry and immunoscoring. Sections of paraffin-embedded tissue specimens $(4 \mu \mathrm{m})$ were subjected to immunostaining using the Ventana automated stainer (BenchMark XT; Roche Diagnostics GmbH, Mannheim, Germany) at the National Institute of Pathology (Baabda, Lebanon). The tissue sections were deparaffinized using xylene, rehydrated through graded ethanols and equilibrated in phosphate-buffered saline before undergoing antigen retrieval. The endogenous peroxidase activity was blocked with $0.3 \%$ hydrogen peroxide for $5 \mathrm{~min}$. The tissue sections were subsequently incubated with the primary mouse monoclonal antibodies at a dilution of 1:200 for $1 \mathrm{~h}$ at room temperature: anti-KLF4 antibody (SAB5300069; clone 1E6), and anti-HSP27 antibody (SAB3701437; clone G3.1) (both from Sigma-Aldrich, St. Louis, MO, USA). The appropriate secondary antibody was horseradish peroxidase (HRP)-conjugated rabbit anti-mouse $\mathrm{IgG}$ (A9044; Sigma-Aldrich) at a dilution of 1:200 for $1 \mathrm{~h}$ at room temperature. The HRP detection was achieved with 3,3'-diaminobenzidine substrate (Sigma-Aldrich) and counterstained with hematoxylin.

Two investigators (G.A. and E.H.) independently scored the slides in a blinded manner. A quantitative score was performed 

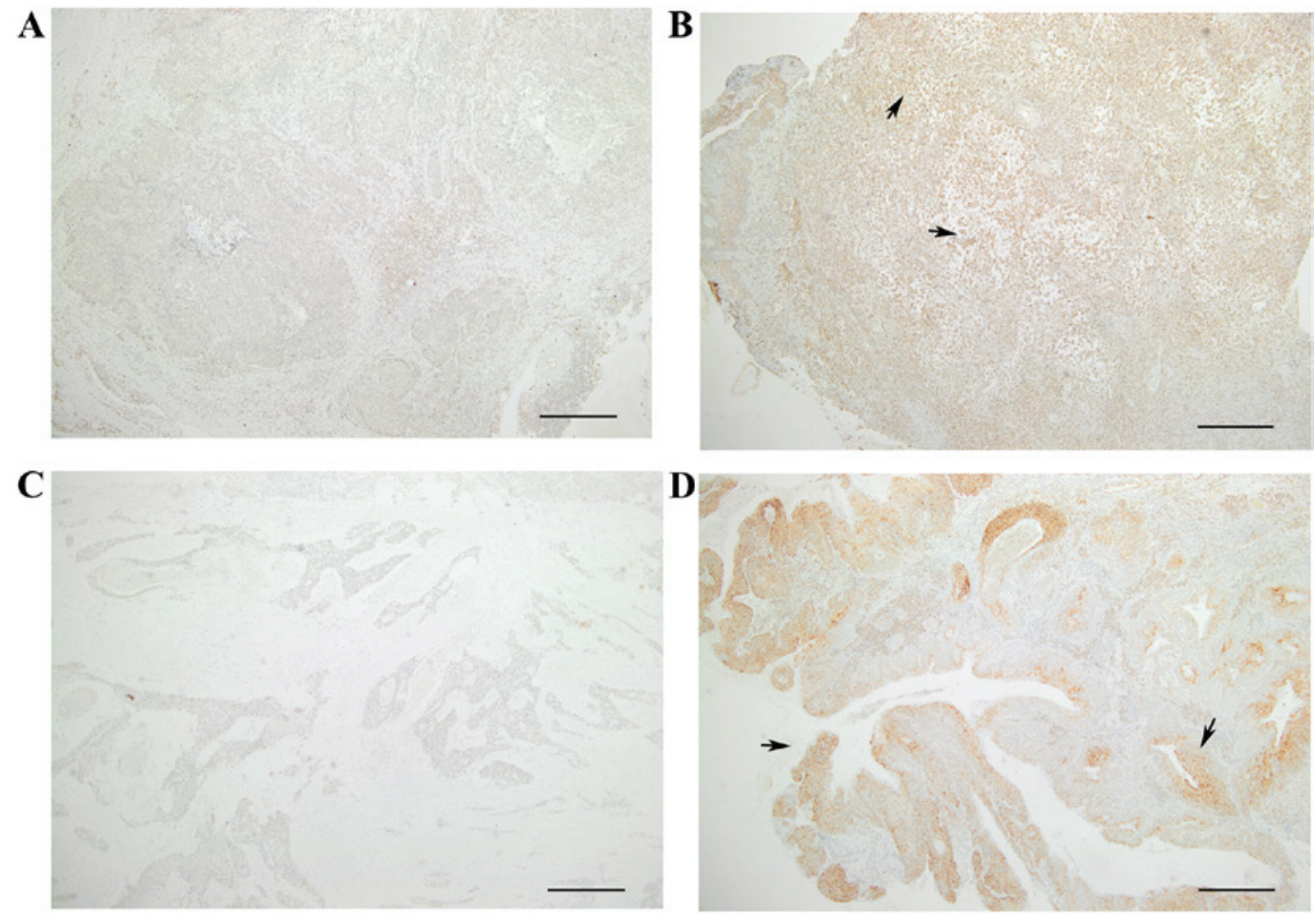

Figure 1. Immunohistochemical analysis of Krüppel-like factor 4 and Heat Shock Protein 27 in larynx tissues. Representative tumor tissue sections with (A) negative KLF4 expression, (B) intense positive KLF4 expression in tumor cells (arrow), (C) negative HSP27 expression, and (D) intense positive HSP27 expression at basal layer (arrow). Magnification x40; scale bar, $52 \mu \mathrm{m}$.

by adding the score of the staining area and the score of staining intensity for each case to assess the expression levels of KLF4 and HSP27. The quantitative score was estimated by calculating the percentage of immunopositive cells as follows: 0 , no staining of cells in any microscopic fields; $1+,<30 \%$ of tissue stained positive; $2+$, between 30 and $60 \%$ stained positive; and $3+,>60 \%$ stained positive. The intensity of staining was scored by evaluating the average staining intensity of the positive cells: 0 , no staining; $1+$, mild staining; $2+$, moderate staining; and $3+$, intense staining .

$R N A$ extraction and reverse transcriptase-quantitative PCR analysis. Total RNA extraction from formalin-fixed paraffin-embedded tissue sections $(20 \mu \mathrm{m})$ was performed using GenElute ${ }^{\mathrm{TM}}$ FFPE RNA Purification kit (RNB400; Sigma-Aldrich) according to the manufacturer's instructions. RNA $(2 \mu \mathrm{g})$ was reverse transcribed using iScript ${ }^{\mathrm{TM}}$ cDNA Synthesis kit (Bio-Rad, Hercules, CA, USA). Reverse transcriptase-quantitative PCR (RT-qPCR) was performed in a CFX96 ${ }^{\mathrm{TM}}$ Real-Time System using $\mathrm{iQ}^{\mathrm{TM}} \mathrm{SYBR}^{\circledR}$ Green Supermix (Bio-Rad). The primer sequences used in RT-PCR were: HSP27 reverse, 5'-TCGAAGGTGACTGGGATGGT-3' and forward, 5'-CCCCCATGCCCAAGCTA-3'; KLF4 reverse, 5'-ATGTGTAAGGCGAGGTGGTC-3' and forward, 5'-ACC CACACAGGTGAGAAACC-3'; GAPDH reverse, 5'-TGGTGG TCCAGGGGTCTTAC-3' and forward, 5 '-TTGCCCTCAACG ACCAGTTT-3' (Sigma-Aldrich). The GAPDH gene was used as an internal control for the relative mRNA amount. All the experiments were performed in triplicate and normalized to GAPDH mRNA expression. The relative RNA level was automatically calculated with the $\Delta \Delta \mathrm{Cq}$ method.
Statistical analysis. Statistical analyses were performed using GraphPad Prism 5. The $\chi^{2}$ test, paired t-test, and Fisher test were used to compare the protein and mRNA expression level of KLF4 and HSP27 between tumors and normal tissues and between the different tumor stages. $\mathrm{P}<0.05$ was considered to indicate statistically significant differences $(\mathrm{P}<0.05, \mathrm{P}<0.01$, $\mathrm{P}<0.001)$.

\section{Results}

Patient characteristics. Table I shows the characteristics of the patients. The median age of patients was 65 years and $83.1 \%$ of the patients were male. According to the TNM staging system, $20.5 \%$ were stage I $(n=9), 25 \%$ were stage II $(n=11), 13.6 \%$ were stage III $(n=6)$, and $40.9 \%$ were stage IV $(n=18)$.

Expression levels of KLF4. The immunohistochemical analysis showed that KLF4 was expressed in the nucleus of tumor and normal cells. Representative findings of the immunohistochemical staining are shown in Fig. 1A and B. A significant difference in KLF4 protein expression was observed between normal and cancer tissues $(\mathrm{P}<0.001)$ (Table II). KLF4 expression was significantly lower in tumor tissues compared to normal tissues. The profile of KLF4 protein expression in each tumor stage is shown in Table III. No significant difference of expression was observed between stages. The protein expression of KLF4 in stage I is similar to that in normal tissues. It decreases in stages II and III, and was mostly downregulated in stage IV tumors (Table III). To determine whether this decrease of the protein expression occurred at the transcriptional level, the KLF4 mRNA levels were evaluated 
Table III. Profile of KLF4 protein expression in the tumor stages (cases per intensity of expression).

\begin{tabular}{lcccc}
\hline & \multicolumn{4}{c}{ KLF4 protein expression, $\mathrm{n}(\%)$} \\
Stage (n) & 0 (no staining) & 1+ (mild staining) & 2+ (moderate staining) & 3+ (intense staining) \\
\hline I (9) & $4(44.5)$ & $2(22.2)$ & $1(11.1)$ & $2(22.2)$ \\
II (11) & $5(45.4)$ & $3(27.3)$ & $3(27.3)$ & 0 \\
III (6) & $3(50.0)$ & $1(16.7)$ & $2(33.3)$ & 0 \\
IV (18) & $15(83.2)$ & $1(5.6)$ & $1(5.6)$ & $1(5.6)$ \\
\hline
\end{tabular}

Table IV. Results of HSP27 immunostaining in normal and tumor tissues (cases per intensity of expression).

\begin{tabular}{lccc}
\hline $\begin{array}{l}\text { Protein } \\
\text { expression }\end{array}$ & $\begin{array}{c}\text { Normal } \\
\text { tissue }(\%)\end{array}$ & $\begin{array}{c}\text { Tumor } \\
\text { tissue }(\%)\end{array}$ & $\begin{array}{c}\text { P-value } \\
\text { (normal vs. tumor) }\end{array}$ \\
\hline 0 & $5(23.8)$ & $0(0)$ & $<0.001$ \\
$1+$ & $15(71.4)$ & $1(2.3)$ & $>0.05$ \\
$2+$ & $1(4.8)$ & $19(43.2)$ & $<0.001$ \\
$3+$ & $0(0)$ & $24(54.5)$ & $<0.001$ \\
\hline
\end{tabular}

in normal and cancer tissues by quantitative real-time PCR analysis. A significant lower KLF4 mRNA copy numbers were found in tumor tissues compared to normal tissues $(\mathrm{P}=0.0058)$, in the same manner as for the protein expression (Fig. 2). These results showed that KLF4 expression was downregulated in laryngeal tumors not only at the protein level but also at the RNA level.

Expression levels of HSP27. The immunohistochemical staining showed that HSP27 is mainly expressed in the cytoplasm at a significant difference of intensities between normal and tumor sections. Examples of the immunohistochemical staining for HSP27 are shown in the Fig. 1C and D. As shown in Table IV, HSP27 was significantly overexpressed in tumor tissues compared to normal tissues $(\mathrm{P}<0.001)$. A significant gradual increase in the HSP27 protein expression was observed from stage I to stage IV (Table V) $(\mathrm{P}=0.0039)$. These results were confirmed by quantitative real-time PCR analysis showing that HSP27 was also up-regulated at RNA level in larynx cancers (Fig. 3). The HSP27 copy numbers were significantly higher in cancer tissue sections compared to normal tissue sections $(\mathrm{P}=0.0115)$.

Factors associated with KLF4 and HSP27 expression levels. In order to determine any correlation of KLF4 and HSP27 expression levels with age and gender, a statistical analysis was performed. KLF4 and HSP27 expression levels were not found to be significantly associated with age or gender.

\section{Discussion}

Laryngeal carcinoma is the second most common malignancy among head and neck tumors. Although the clinical outcome of laryngeal carcinoma has gradually improved, the prognosis

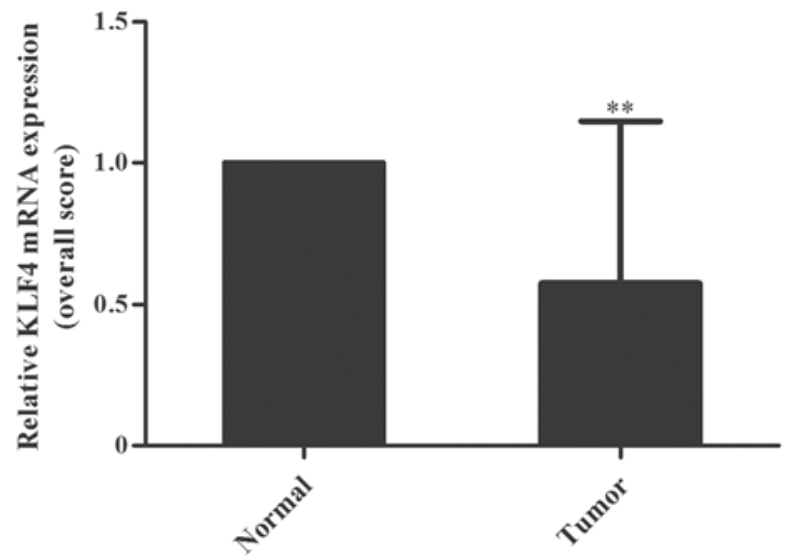

Figure 2. KLF4 mRNA expression in normal and tumor larynx tissues. KLF4 mRNA expression levels were significantly decreased in larynx tumor tissues compared with normal tissues $\left({ }^{* *} \mathrm{P}=0.0058\right)$.

of this tumor remains poor. A better understanding of the molecular mechanisms and key molecules driving laryngeal carcinogenesis may aid in the identification of novel predictive and prognostic biomarkers, and in the development of novel treatment strategies for this cancer. The role of KLF4 and HSP27 as possible biomarkers and therapy targets has been extensively investigated in various types of cancer $(33,34)$. However, the aberrant expression of these proteins in laryngeal squamous cell carcinoma (LSCC) is poorly understood. In the present study, the expression profile and the potential role of these proteins as possible biomarkers of LSCC were investigated.

In this study, we examined the expression of KLF4 and HSP27 in a series of human laryngeal tumors and normal tissues. The expression profile of these proteins indicated that they are significantly regulated in LSCC. The protein and mRNA expression levels of KLF4 were significantly decreased in LSCC compared to those in normal tissue, while HSP27 was significantly overexpressed in tumor compared to normal tissues, at the protein and mRNA levels. Regarding tumor stages, the expression of the two proteins varies in an opposite manner. The KLF4 expression decreases gradually with tumor progression suggesting that KLF4 expression is lost as the tumor progresses, while HSP27 expression increases with stages, showing a significant difference between stages I and IV. These findings suggest that KLF4 and HSP27 may be opposite functions and roles in the carcinogenic process of LSCC. KLF4 seems to play a tumor suppressing role in 
Table V. Profile of HSP27 protein expression in the tumor stages (cases per intensity of expression).

Hsp27 protein expression, n (\%)

\begin{tabular}{lcccc}
\cline { 2 - 4 } Stage (n) & 0 (no staining) & 1+ (mild staining) & 2+ (moderate staining) & 3+ (intense staining) \\
\hline I (9) & 0 & $1(11.1)$ & $6(66.7)$ & $2(22.2)$ \\
II (11) & 0 & 0 & $5(45.5)$ & $6(54.5)$ \\
III (6) & 0 & 0 & $4(66.7)$ & $2(33.3)$ \\
IV (18) & 0 & 0 & $4(22.2)$ & $14(77.8)$ \\
\hline
\end{tabular}

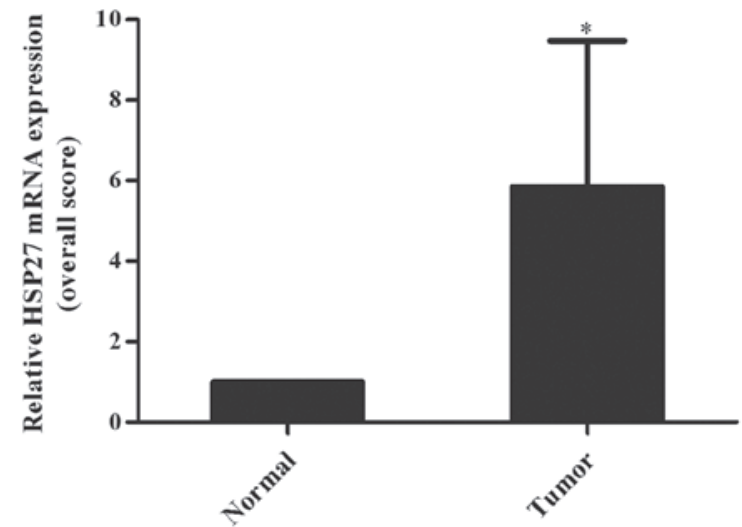

Figure 3. HSP27 mRNA expression levels in normal and tumor larynx tissues. HSP27 mRNA expression levels were significantly increased in larynx tumor tissues compared with normal tissues $\left({ }^{*} \mathrm{P}=0.0115\right)$.

LSCC, while HSP27 seems to play an oncogenic role and its overexpression may contribute in the initiation of the disease and its progression and aggressiveness. The downregulation of KLF4 in LSCC may be associated with promoter hypermethylation, a loss of heterozygosity of the KLF4 locus, or with point mutations in the coding region. Epigenetic control and gene network may play a role in the decrease of KLF4 levels in laryngeal cancers. The decrease in its expression in stage IV was associated with increased tumor differentiation and aggressiveness. The mechanisms underlying this downregulation require elucidation by future studies.

The aberrant expression of KLF4 has been reported in various forms of cancer. However, no previous studies have examined the expression level of KLF4 in laryngeal carcinoma. To the best of our knowledge, the present study is the first to provide a preliminary description of the profile of expression of KLF4 and its potential role in laryngeal carcinogenesis. This is the first study showing a significant difference in KLF4 protein and mRNA expression levels between normal and cancerous laryngeal tissues. Our findings were consistent with those reported by different studies showing a tumor suppressor role of KLF4 in several types of cancer, including gastric and colon cancers (6-8), bladder cancer (35), esophageal cancer (36), and non small cell lung carcinoma $(14,37)$. Of note, in head and neck squamous cell carcinoma malignancies, KLF4 can exert different roles in different types. In oral squamous cell carcinoma, the expression of KLF4 increases at the early stages of the disease where it plays an oncogenic role (38). However, in our study on LSCC, opposite results were obtained. The expression of KLF4 appears to exert a dual effect depending on the cell context and gene network. Our actual in vitro study aims to determine the underlying mechanisms and the potential factors that regulate the gene or the protein expression of KLF4.

The expression level and role of HSP27 have been considerably investigated by several studies that reported a higher expression level of this protein in tumors from various origins, associated with tumor aggressiveness and poor survival of patients. HSP27 is clearly involved in the tumorigeneis process, tumor resistance and progression, and metastasis. It is considered as a promising therapeutic target (39). Its gene inhibition using antisense oligonucleotide showed a promising therapeutic effect in clinical application (30). HSP27 has been identified as a candidate biomarker. Some studies have explored its potential prognostic value and its role in predicting the adequate therapy (16). However, studies regarding the role of HSP27 in larynx cancer are limited $(31,32)$. In the present study, the expression of HSP27 increases significantly in larynx tumor tissues compared with normal tissues. This expression is correlated to tumor stages, confirming the role of this protein in oncogenic transformation and tumor progression. The level of HSP27 seems to be associated with the level of tumor differentiation. These findings are consistent with recent studies investigating HSP27 expression in cancer and elucidating its prognostic role.

Our results were not consistent with those of $\mathrm{Xu}$ et al, that showed an absence of significant difference in HSP27 protein expression between laryngeal carcinoma and normal controls (32). This discrepancy may be due to the marginally larger tumor sample collection in our study, potentially contributing to more relevant results, and to the different method used to evaluate HSP27 expression. Our observations were also not consistent with those of Kaigorodova et al who demonstrated a high nuclear expression of the phosphorylated and unphosphorylated forms of HSP27 in the biopsies of patients with lymph node metastases (31). However, the cytoplasmic expression of HSP27 in these patients did not differ statistically, and in their study, they did not evaluate the mRNA expression level of HSP27 in their larynx tissues.

Since HSP27 is upregulated from early stages of the disease and KLF4 is downregulated progressively and specially in advanced stages, this implies that HSP27 might suppress the expression of KLF4 probably through indirect mechanisms. In fact, a study showed that HSP27 interacts with SP1 in the brain (40) which is a transcription factor of the KLF/SP family that can activate the transcription of KLF4 $(41,42)$. This 
interaction was shown to potentiate the transcription activity of SP1, and had a cytoprotective role for the neurons (40). In laryngeal carcinoma, HSP27 could interact with SP1 and thus preventing SP1 from activating the transcription of KLF4. Our actual in vitro study aims to elucidate the presence of this link between these two proteins and the underlying mechanisms and factors or protein partners implied in this regulation. To date, neither KLF4 nor HSP27 have been extensively studied in laryngeal cancer. This is the first study that investigated the expression and role of KLF4 in larynx cancer, and that showed a potential association between KLF4 and HSP27 in this type of cancer. However, due to the lack of patient survival data, we were unable to investigate any correlation between immunohistochemical and RTPCR findings and patient survival.

Understanding the molecular mechanisms underlying the pathogenesis of larynx cancer is required to achieve better patient outcomes. The role of HSP27 and KLF4 in larynx cancer initiation and progression highlights their use as potential future targets for prognosis and treatment.

\section{Acknowledgements}

The present study has been funded with support from the National Council for Scientific Research in Lebanon and from the Lebanese University.

\section{References}

1. Santos TS, Estêvão R, Antunes L, Certal V, Silva JC and Monteiro E: Clinical and histopathological prognostic factors in locoregional advanced laryngeal cancer. J Laryngol Otol 130: 948-953, 2016.

2. Marur S and Forastiere AA: Head and neck squamous cell carcinoma: Update on epidemiology, diagnosis, and treatment. Mayo Clin Proc 91: 386-396, 2016.

3. Ding B, Liu P, Liu W, Sun P and Wang CL: Emerging roles of Krüppel-like factor 4 in cancer and cancer stem cells. Asian Pac J Cancer Prev 16: 3629-3633, 2015.

4. Evans PM and Liu C: Roles of Krüpel-like factor 4 in normal homeostasis, cancer and stem cells. Acta Biochim Biophys Sin (Shanghai) 40: 554-564, 2008.

5. Rowland BD and Peeper DS: KLF4, p21 and context-dependent opposing forces in cancer. Nat Rev Cancer 6: 11-23, 2006.

6. Zhao W, Hisamuddin IM, Nandan MO, Babbin BA, Lamb NE and Yang VW: Identification of Krüppel-like factor 4 as a potential tumor suppressor gene in colorectal cancer. Oncogene 23 395-402, 2004.

7. Wei D, Gong W, Kanai M, Schlunk C, Wang L, Yao JC, Wu TT, Huang S and Xie K: Drastic down-regulation of Krüppel-like factor 4 expression is critical in human gastric cancer development and progression. Cancer Res 65: 2746-2754, 2005.

8. Wei D, Kanai M, Huang S and Xie K: Emerging role of KLF4 in human gastrointestinal cancer. Carcinogenesis 27: 23-31, 2006.

9. Hu W, Hofstetter WL, Li H, Zhou Y, He Y, Pataer A, Wang L, Xie K, Swisher SG and Fang B: Putative tumor-suppressive function of Kruppel-like factor 4 in primary lung carcinoma. Clin Cancer Res 15: 5688-5695, 2009.

10. Pandya AY, Talley LI, Frost AR, Fitzgerald TJ, Trivedi V, Chakravarthy M, Chhieng DC, Grizzle WE, Engler JA, Krontiras H, et al: Nuclear localization of KLF4 is associated with an aggressive phenotype in early-stage breast cancer. Clin Cancer Res 10: 2709-2719, 2004.

11. Chen CJ, Lin SE, Lin YM, Lin SH, Chen DR and Chen CL: Association of expression of kruppel-like factor 4 and kruppel-like factor 5 with the clinical manifestations of breast cancer. Pathol Oncol Res 18: 161-168, 2012.

12. Rowland BD, Bernards R and Peeper DS: The KLF4 tumour suppressor is a transcriptional repressor of p53 that acts as a context-dependent oncogene. Nat Cell Biol 7: 1074-1082, 2005.
13. Tai SK, Yang MH, Chang SY, Chang YC, Li WY, Tsai TL, Wang YF, Chu PY and Hsieh SL: Persistent Krüppel-like factor 4 expression predicts progression and poor prognosis of head and neck squamous cell carcinoma. Cancer Sci 102: 895-902, 2011.

14. Fadous-Khalifé MC, Aloulou N, Jalbout M, Hadchity J, Aftimos G, Paris F and Hadchity E: Krüppel-like factor 4: A new potential biomarker of lung cancer. Mol Clin Oncol 5: 35-40, 2016.

15. Zoubeidi A and Gleave M: Small heat shock proteins in cancer therapy and prognosis. Int J Biochem Cell Biol 44: 1646-1656, 2012.

16. Lianos GD, Alexiou GA, Mangano A, Mangano A, Rausei S, Boni L, Dionigi G and Roukos DH: The role of heat shock proteins in cancer. Cancer Lett 360: 114-118, 2015.

17. Kaigorodova EV and Bogatyuk MV: Heat shock proteins as prognostic markers of cancer. Curr Cancer Drug Targets 14: 713-726, 2014.

18. Sherman M and Multhoff G: Heat shock proteins in cancer. Ann N Y Acad Sci 1113: 192-201, 2007.

19. Ciocca DR, Arrigo AP and Calderwood SK: Heat shock proteins and heat shock factor 1 in carcinogenesis and tumor development: An update. Arch Toxicol 87: 19-48, 2013.

20. Lo WY, Tsai MH, Tsai Y, Hua CH, Tsai FJ, Huang SY, Tsai CH and Lai CC: Identification of over-expressed proteins in oral squamous cell carcinoma (OSCC) patients by clinical proteomic analysis. Clin Chim Acta 376: 101-107, 2007.

21. Cordonnier T, Bishop JL, Shiota M, Nip KM, Thaper D, Vahid S, Heroux D, Gleave M and Zoubeidi A: Hsp27 regulates $\mathrm{EGF} / \beta$-catenin mediated epithelial to mesenchymal transition in prostate cancer. Int J Cancer 136: E496-E507, 2015.

22. Shiota M, Bishop JL, Nip KM, Zardan A, Takeuchi A, Cordonnier T, Beraldi E, Bazov J, Fazli L, Chi K, et al: Hsp27 regulates epithelial mesenchymal transition, metastasis and circulating tumor cells in prostate cancer. Cancer Res 73: 3109-3119, 2013.

23. Stope MB, Weiss M, Preuss M, Streitbörger A, Ritter CA, Zimmermann U, Walther R and Burchardt M: Immediate and transient phosphorylation of the heat shock protein 27 initiates chemoresistance in prostate cancer cells. Oncol Rep 32: 2380-2386, 2014

24. Hansen RK, Parra I, Lemieux P, Oesterreich S, Hilsenbeck SG and Fuqua SA: Hsp27 overexpression inhibits doxorubicin-induced apoptosis in human breast cancer cells. Breast Cancer Res Treat 56: 187-196, 1999.

25. Hsu HS, Lin JH, Huang WC, Hsu TW, Su K, Chiou SH, Tsai YT and Hung SC: Chemoresistance of lung cancer stemlike cells depends on activation of Hsp27. Cancer 117: 1516-1528, 2011.

26. Ciocca DR and Calderwood SK: Heat shock proteins in cancer: Diagnostic, prognostic, predictive, and treatment implications. Cell Stress Chaperones 10: 86-103, 2005.

27. Hadchity E, Aloy MT, Paulin C, Armandy E, Watkin E, Rousson R, Gleave M, Chapet $\mathrm{O}$ and Rodriguez-Lafrasse C: Heat shock protein 27 as a new therapeutic target for radiation sensitization of head and neck squamous cell carcinoma. Mol Ther 17: 1387-1394, 2009.

28. Aloy MT, Hadchity E, Bionda C, Diaz-Latoud C, Claude L, Rousson R, Arrigo AP and Rodriguez-Lafrasse C: Protective role of Hsp27 protein against gamma radiation-induced apoptosis and radiosensitization effects of Hsp27 gene silencing in different human tumor cells. Int J Radiat Oncol Biol Phys 70: 543-553, 2008.

29. Lelj-Garolla B, Kumano M, Beraldi E, Nappi L, Rocchi P, Ionescu DN, Fazli L, Zoubeidi A and Gleave ME: Hsp27 inhibition with OGX-427 sensitizes non-small cell lung cancer cells to erlotinib and chemotherapy. Mol Cancer Ther 14: 1107-1116, 2015.

30. Chi KN, Yu EY, Jacobs C, Bazov J, Kollmannsberger C, Higano CS, Mukherjee SD, Gleave ME, Stewart PS and Hotte SJ: A phase I dose-escalation study of apatorsen (OGX-427), an antisense inhibitor targeting heat shock protein 27 (Hsp27), in patients with castration-resistant prostate cancer and other advanced cancers. Ann Oncol 27: 1116-1122, 2016.

31. Kaigorodova EV, Zavyalova MV, Bychkov VA, Perelmuter VM and Choynzonov EL: Functional state of the Hsp27 chaperone as a molecular marker of an unfavorable course of larynx cancer. Cancer Biomark 17: 145-153, 2016.

32. Xu X, Zhao M and Shi Y: Expression of heat shock proteins in laryngeal carcinoma. Zhonghua Er Bi Yan Hou Ke Za Zhi 33: 232-234, 1998 (In Chinese) 
33. Ghaleb AM and Yang VW. Krüppel-like factor 4 (KLF4): What we currently know. Gene 611:27-37, 2017.

34. Wu J, Liu T, Rios Z, Mei Q, Lin X and Cao S: Heat Shock Proteins and Cancer. Trends Pharmacol Sci 38:226-256, 2017.

35. Ohnishi S, Ohnami S, Laub F, Aoki K, Suzuki K, Kanai Y, Haga K, Asaka M, Ramirez F and Yoshida T: Downregulation and growth inhibitory effect of epithelial-type Krüppel-like transcription factor KLF4, but not KLF5, in bladder cancer. Biochem Biophys Res Commun 308: 251-256, 2003.

36. Wang N, Liu ZH, Ding F, Wang XQ, Zhou CN and Wu M: Down-regulation of gut-enriched Kruppel-like factor expression in esophageal cancer. World J Gastroenterol 8: 966-970, 2002.

37. Zhang Z, Wang Z, Liu X, Shi M, Chen G, Zhang B, Li Z and Song L: Correlation of KLF4 and SPARC expression with the clinical characteristics of non-small cell lung cancer. Zhongguo Fei Ai Za Zhi 15: 720-724, 2012 (In Chinese).

38. Yoshihama R, Yamaguchi K, Imajyo I, Mine M, Hiyake N, Akimoto N, Kobayashi Y, Chigita S, Kumamaru W, Kiyoshima T, et al: Expression levels of SOX2, KLF4 and brachyury transcription factors are associated with metastasis and poor prognosis in oral squamous cell carcinoma. Oncol Lett 11: 1435-1446, 2016.

39. Acunzo J, Andrieu C, Baylot V, So A and Rocchi P: Hsp27 as a therapeutic target in cancers. Curr Drug Targets 15: 423-431, 2014.

40. Friedman MJ, Li S and Li XJ: Activation of gene transcription by heat shock protein 27 may contribute to its neuronal protection. J Biol Chem 284: 27944-27951, 2009.
41. Deaton RA, Gan Q and Owens GK: Sp1-dependent activation of KLF4 is required for PDGF-BB-induced phenotypic modulation of smooth muscle. Am J Physiol Heart Circ Physiol 296: H1027-H1037, 2009.

42. Zhang JP, Zhang H, Wang HB, Li YX, Liu GH, Xing S, Li MZ and Zeng MS: Down-regulation of Spl suppresses cell proliferation, clonogenicity and the expressions of stem cell markers in nasopharyngeal carcinoma. J Transl Med 12: 222, 2014. 